\title{
Ética de la economía, sujeto y derechos humanos
}

\author{
María Arcelia Gonzáles Butrón
}

Universidad Michoacana de San Nicolás, Morelia, Michoacán, México.

Email: gbutron6@yahoo.com.mx

Resumen: La economía como ciencia social, como ciencia para la vida, está siendo interpelada cotidianamente por los efectos de una generalizada lógica de mercado totalizante que causa muerte y desesperanza a grupos cada vez más amplios de seres humanos y que, enfrenta/destruye la construcción de sujetos. Como respuesta, se impone una mirada crítica, una mirada ética y esfuerzos de diálogo multidisciplinario. En tal sentido se viene desarrollando una investigación de la que se comparten avances en este texto. La primera parte recoge resultados parciales de una indagación -desde una perspectiva de la ética para la vida-, de las razones que se aproximan a explicar la negación del sujeto: desde la economía, desde el pensamiento posmoderno y desde la manipulación de los deseos y el poder. En la segunda parte se reflexionan sobre criterios y opciones para la defensa del sujeto, como sujeto viviente, entendiéndolo como subjetividad-intersubjetividad que no es lo mismo que individualidad. Se trata de recuperar el fundamento de la solidaridad humana y el quehacer económico basado en los derechos humanos.

Palabras clave: Ética, Economía, Sujeto y Derechos Humanos

\section{Ethics of economy, subject and human rights}

\begin{abstract}
Economics as a social science, as a science of life, is being questioned on a daily basis due to the effects of a generalized logic of totalizing market that causes death and despair to increasingly larger groups of human beings; a logic that confronts and destroys the creation of subjects. A critical perspective is raised in response, an ethical point of view as well as attempts of multidisciplinary dialogue. In that sense, a research is being developed of which some is advanced in this text. The first part recovers the partial results of an inquiry -from a perspective of life-supporting ethics- regarding the reasons that attempt to explain the negation of the subject: from an economics' point of view, from the perspective of postmodern thought and from the manipulation of desires and power. The second part includes analysis concerning criteria and options for the defense of the subject as a living subject, understanding him as subjectivity/intersubjectivity, which is not the same as individuality. The goal is to recover the foundation of human solidarity and an economic practice based on human rights.
\end{abstract}

Key words: Ethics, Economics, Subject and Human Rights

\section{Ética do economia, sujeito e direitos humanos}

Resumo: A Economia como uma ciência social, como uma ciência da vida, está sendo questionada diariamente, devido aos efeitos de uma lógica de mercado totalizante generalizada que causa morte e desespero para grupos cada vez maiores 
de seres humanos, uma lógica que confronta e destrói a criação de sujeitos. Uma perspectiva crítica é levantada em resposta, um ponto de vista ético, bem como as tentativas de diálogo multidisciplinar. Nesse sentido, uma pesquisa está sendo desenvolvido a partir do qual um trabalho é compartilhada neste texto. A primeira parte recupera os resultados parciais de uma pesquisa - a partir da perspectiva de uma ética para a vida - respeito das razões que tentam explicar a negação do sujeito: a partir do ponto de vista da economia, da perspectiva do pensamento pós-moderno e da manipulação dos desejos e o poder. A segunda parte inclui a reflexão sobre critérios e opções para a defesa do sujeito como um sujeito vivo, entendendo-os como subjetividade / intersubjetividade, o que não é o mesmo do que a individualidade. O objetivo é recuperar a fundação de solidariedade humana e de um fazer econômico baseado nos direitos humanos.

Palavras-chave: Ética, Economia, Sujeito e Direitos Humanos

\section{Presentación}

Constituye un reto importante el reflexionar sobre el Sujeto en tiempos de la globalización neoliberal, pues esto desencadena un proceso muy importante de revisión de los discursos, de los marcos referenciales, de los paradigmas y, en general, del pensamiento que ha acompañado las prácticas cotidianas contemporáneas de transformación social.

El sujeto lo entendemos aquí como subjetividad, entendida como una identidad con otros y otras; en tal sentido la subjetividad irrumpe en la individualidad. El individuo calcula y como tal, o como grupo, defiende sus intereses particulares. La persona en tanto sujeto también defiende sus intereses pero lo hace en la intersubjetividad establecida por el criterio según el cual la amenaza a la vida del otro/a es también amenaza para la propia vida, aunque “calculablemente” no haya el más minúsculo criterio para sostener eso (Hinkelammert, 2003: 53).

El Sujeto, es un sujeto corporal, una corporeidad con el derecho a tener derechos, Derechos Humanos y, ejercerlos.

Desde diferentes espacios académicos y sociales en general, se han tomado iniciativas importantes para producir textos colectivos atendiendo a preocupaciones intelectuales comunes en torno al sujeto en el contexto de recrudecimiento de la estrategia de globalización neoliberal que amenaza la existencia planetaria generando cada vez mayor dolor social. Pero también, se están tratando de recuperar las nuevas propuestas utópicas emergentes desde los/as excluídos/as como las de los/as indígenas zapatistas y, actualmente también desde la comunidad de Cherán en Michoacán: llamados a la inclusión, a construir comunidad, ante la negación persistente del sujeto por parte de los grupos económicos dominantes.

Este es un desafío ante la agudización de las distintas expresiones del dolor social. Pero, nos preguntamos con frecuencia ¿cómo podemos 
tolerarlo sin reaccionar con la misma intensidad de su impacto? ¿cómo un sistema económico y social de capitalismo salvaje se puede estar imponiendo mundialmente, globalmente, sin que se generen las resistencias necesarias para oponerse a su lógica de muerte? Hay necesidad de respuestas, de razones explicativas que permitan ir construyendo y dando razones de esperanza.

No podemos desconocer ni dejar de valorar diversas movilizaciones sociales a nivel mundial, como los movimientos de los indignados, que tratan de revertir las tendencias económicas dominantes. Desde la academia apreciamos que el reto es muy grande pero debemos responder consecuentemente, generando nuevos conocimientos, no sólo nuevas herramientas de análisis sino pensamiento crítico al menos de modo multidisciplinario. Intentamos con este artículo contribuir modestamente a una reflexión necesaria, a una mirada ética de la economía.

\section{Indagando las razones de la negación del sujeto}

Estas razones pueden indagarse desde varias vertientes. Se han elegido tres que consideramos indispensables.

\section{Desde la economía: algunos fundamentos del nuevo modelo capitalista, sus protagonistas y sus consecuencias}

Aunque prevalece un importante debate sobre las características del nuevo modelo económico dominante se coincide respecto a sus fundamentos últimos que se sustentan en el liberalismo económico. Para J. Valenzuela Feijóo el reordenamiento económico estructural es coherente con un proyecto político específico que es recubierto ideológicamente por el Fondo Monetario Internacional (FMI). Desde un ángulo teórico muy general, esta ideología se asienta en principios walrasianos, tales como: a) la economía capitalista tiende espontáneamente a una situación de equilibrio estable; b) tal equilibrio se corresponde con una plena utilización de los recursos productivos; c) la asignación de los recursos es óptima y, por tanto, da lugar a la maximización del dividendo social (Valenzuela, 1991: 16). Según el mismo autor, la coherencia interna de este esquema ha sido fuertemente criticada por Sraffa, Garegnani y otros, además de que la evidencia empírica contrasta con tales principios, sin embargo se ha insistido en ellos y se vienen imponiendo ya no por consideraciones científicas sino por afanes político-doctrinarios.

Sobre la base de los principios de la teoría neoclásica, teóricos como Karl Popper y Friedrich Hayek profundizaron marcos sustentadores, fundamentaron y justificaron una perspectiva epistemológica, e inclusive, según R. Gómez "elevaron el modus operandi de la economía neoclásica, y le dieron el status de método universal para las ciencias sociales" (Gómez, 1995: 159). De allí que se intente actualmente generalizar el método de la teoría económica “neoliberal” -pragmática y con el horizonte de totalización 
del Mercado- a las otras ciencias sociales. Se pretende reivindicar una suerte de darwinismo social que justifica la exclusión económica de muchos seres humanos en una lógica de Mercado apoyada en una "racionalidad científica” supuestamente neutra y objetiva.

Popper y Hayek sustentan de este modo la preferencia por una determinada teoría económica ligada a un programa político: el del liberalismo neoclásico, el cual sería retomado con algunas modificaciones por la escuela de Chicago, especialmente planteado por Milton Friedman y exportado como "objetivamente científico" a todos aquéllos que pretendan acceder al paraíso consumista del llamado primer mundo (Gómez, 1995: 160). Con este último economista la propuesta liberal neoclásica no avanza sustancialmente en el plano teórico pero sí en su formalización: con el uso extenso de la econometría y las matemáticas financieras trata de acumular la mayor evidencia empírica que demuestre la verificación de algunas de sus hipótesis básicas como son la posibilidad de maximización de ganancias y la existencia de condiciones de equilibrio sin intervención estatal.

De modo general, los supuestos más importantes de la concepción neoliberal de la economía que Popper, Hayek y Friedman comparten son los siguientes:

- Toda realidad, y en particular la realidad social, es un conjunto que resulta del agregado de elementos interrelacionados por situaciones que operan exclusivamente entre dichos elementos individuales.

- La sociedad es sólo el nombre del conjunto de los individuos que la componen, ligados entre sí especialmente por un sistema de tradiciones homogéneas.

- El ser humano es básicamente un ser egoísta, consumidor y propietario de sus bienes.

- El ser humano es un ser de tradiciones, la primera, la que resulta de su naturaleza básicamente egoísta; la segunda, la de la ciencia.

- Los seres humanos son naturalmente desiguales. La única igualdad válida es la igualdad política ante el mercado y la ley.

- La libertad es abstracta, individual y negativa.

-El mercado es el único ordenador racional y la planificación es irracional.

- La democracia es el sistema político recomendable en tanto no interfiera con el funcionamiento del libre mercado.

-La sociedad capitalista neoliberal es insuperable.

Este conjunto de supuestos tienen consecuencias y efectos prácticos muy trascendentes para entender la situación actual, son aceptados -explícita o implícitamente- por los principales centros del capitalismo contemporáneo y pretenden imponerse a todos los rincones del planeta.

Se traducen por ejemplo en la propuesta de liberalización económica, según la cual, la asignación económica de los recursos debe ser resultante de la operación espontánea de las fuerzas del mercado. En la tradi- 
ción clásica esto se entiende en el sentido de aceptar la ley del valor como mecanismo central de regulación económica. En el plano más abstracto, a este principio se opone el de la planificación (Valenzuela, 1991: 17-18). Contradictoriamente, en la práctica no se acepta la intervención estatal pero sí la intervención y planificación oligopólica, favoreciendo el mecanismo de competencia. También se observa en la actualidad cómo el liberalismo económico se combina con formas políticas muy poco liberales y sí intervencionistas, condicionadoras y coactivas.

Por otro lado, el proyecto o "paquetes neoliberales" impulsados en América Latina, desde los ochenta están fuertemente asociados al plano de recuperación hegemónica y de reestructuración global impulsado por los sectores dominantes de Estados Unidos, del G-8 (incluyendo a Rusia) y del Foro de Davos, por citar algunos espacios significativos.

Lo que está de fondo en juego es la defensa feroz de la lógica esencial del capitalismo que es la lógica de valorización del capital cuyo grado de valorización se mide por la tasa de ganancia, de allí que las fluctuaciones de ésta regulen las fluctuaciones de la acumulación y del nivel de la actividad económica. En una crisis, cuando se habla de recuperación se está haciendo referencia justamente a la recuperación de la caída de la tasa de ganancia; no del poder adquisitivo de la mayoría de la población.

Este es un aspecto muy importante para entender el papel de la fuerza de trabajo y de los salarios en esta lectura. Se sabe que la vía por excelencia para reconstituir la tasa de ganancia es aumentar la tasa de plusvalía a través de la reducción de los salarios reales. El enfoque monetarista recomienda recurrir a los mecanismos de reducción de los salarios reales también por la vía de la desocupación. Es importante tener en cuenta que para reducir los salarios reales hay dos grandes vías: la coacción extraeconómica (por la fuerza de las armas por lo general) y por la más propiamente económica que es propiciando la desocupación estructural.

Si bien esto requiere análisis particulares en cada realidad económica, un hecho mundial hoy incuestionable es el enorme incremento de la desocupación desde la década del ochenta, acentuada en los noventa y persistente en los primeros años del siglo XXI, tanto en los países del sur como en los países del norte y, como se explica anteriormente, esto no es accidental sino consustancial al modelo económico dominante.

También es clara la tendencia al congelamiento y disminución del precio de la fuerza de trabajo, a pesar de la política de liberación general de precios.

Así pues, en esta lógica se explica el porqué de la reducción de los salarios reales y también, consecuentemente, bajo el modelo neoliberal se explican fenómenos como el desempleo, el subempleo, la distribución cada vez más regresiva del ingreso y, en última instancia, los procesos de exclusión económica. No son pues problemas circunstanciales o coyunturales 
como lo plantean casi todos los gobiernos conservadores, se trata de componentes y comportamientos del nuevo modelo, de lo que algunos/as economistas destacados llamaron un nuevo patrón de acumulación.

Estos fundamentos tuvieron efectos prácticos en América Latina pues a fines de los setenta y más definidamente en los ochenta sus economías transitaron por profundos procesos de reorientación y transformación económica que cambiaron radicalmente el panorama económico social para las décadas que siguieron.

En términos generales, un capitalismo desarrollista e intervencionista expresado, con diversas particularidades en el modelo de sustitución de importaciones, fue transformado hacia una modalidad abierta y no intervencionista. Las políticas de ajuste estructural y sus correspondientes programas han ido conduciendo a cambios estructurales de largo plazo más que a "ajustes" coyunturales o de corto plazo. Las consecuencias sociales de estos cambios son evidentes.

La política de capitalismo extremo -política de mercado total- surgida en la década de los 70, sirvió a partir de 1982 para estructurar las economías de América Latina en función de la transferencia de un excedente maximizado hacia los países del centro, quienes son los dueños de la deuda externa de América Latina. La tesis del ajuste estructural se reformuló a partir de 1982 en el sentido de un capitalismo extremo orientado a crear las condiciones estructurales para transferir desde América Latina hacia los países desarrollados del centro, un excedente lo mayor posible. Ajuste estructural significa ahora: transformación de América Latina en función de un capitalismo extremo capaz de transferir a los países del centro un máximo de excedentes. La denominación de "ajuste estructural” se refiere a esta política, que pone la transformación del capitalismo hacia el mercado total al servicio de la transferencia de un excedente máximo hacia los centros del mundo capitalista. (Hinkelammert 1990: 32)

Esta perspectiva del denominado capitalismo extremo estuvo ya claramente presente en los setenta y, más particularmente, la crisis de los ochenta parecía convencer a muchos gobiernos de la urgencia del cambio estructural propuesto por los organismos financieros internacionales.

Con el pretexto -por cierto real- de la crisis de la deuda a principios de los ochenta, la oportunidad para el desarrollo rápido de los "ajustes estructurales” no se hizo esperar en toda la región, lo cual fue justificado políticamente dados los fuertes desequilibrios manifiestos en nuestras economías, expresados especialmente en intensos procesos inflacionarios, fuertes déficits gubernamentales y recesión económica.

Lo que estaba ocurriendo en realidad eran transformaciones profundas en el modelo económico vigente. La sustitución de importaciones, el 
fortalecimiento del mercado interno y, por tanto, los intentos de desarrollo nacional estaban siendo completamente abandonados para dar paso a economías más orientadas al fomento de las exportaciones, al fortalecimeinto de mercados externos y al desarrollo de los centros de poder económico internacional.

La política del desarrollo es ahora sustituida por la política de la extracción del máximo de excedentes, pase lo que pase con el desarrollo de América Latina. Esta política recibe el nombre de ajuste estructural. Ya no se habla más de desarrollo, sino de los mercados. Tampoco se habla más de dependencia, porque la dependencia ha aumentado de tal manera que ya se puede impedir hablar de ella. De lo que sí se habla, es de la necesidad de pagar aportes de capital... (Hinkelammert, 1990: 34)

Se trata de lograr, a través de ajustes estructurales, economías más integradas a la lógica predominante del mercado mundial.

Esta orientación clara hacia el mercado exterior y al abandono de los objetivos nacionales de desarrollo interno tiene algunos límites, de allí la importancia que reviste el nuevo papel del Estado en nuestras economías.

\section{El nuevo papel del Estado, los grupos económicos que impulsan el nuevo modelo y los/as excluídos/as}

Segun Joan Nelson, muchas medidas de ajuste estructural, si bien son impuestas desde afuera, no están enteramente, o ni siquiera ampliamente, dentro del control de las autoridades económicas centrales: necesitan aprobación legislativa, suponen consensos, negociación y hasta represión. Requieren, en suma, la intervención del Estado. Aunque los voceros del neoclasicismo arguyen que la liberalización económica exige un Estado más disminuido, menos intervencionista, se ha tornado cada vez más evidente que el reanudado y sostenible crecimiento requiere también unas acrecentadas capacidades estatales: no tanto un Estado mucho menos poderoso, como uno que desempeñe diferentes papeles y haga ésto con más eficacia (Nelson y otros, 1991: 12).

Esto puede comprenderse más cuando se analizan los protagonistas y los excluídos de la propuesta neoliberal. Desde los noventa quedó claro que el nuevo modelo se asentaba en el capital transnacional y una delgada capa de capitalistas nacionales. Estos funcionan como una oligarquía financiera en cuyo seno se privilegian los espacios circulatorios. En cuanto a las ramas o sectores de desarrollo preferente, amén de los financieros e improductivos, deben priorizarse los sectores de exportación, primarios y semimanufactureros (Valenzuela, 1999: 153-154).

Para América Latina, la lógica del cambio estructural y de los modos y ritmos de acumulación en Estados Unidos son determinantes para la 
manera en que se continúen integrando nuestras economías hacia y en el objetivo de la mayor transferencia posible de excedentes. Esto va determinando también a los núcleos y grupos sociales incluidos en la propuesta, que son justamente los que mejor responden a esta lógica desde las economías nacionales.

De allí que sean muy importantes los grupos exportadores nacionales, los grandes agroexportadores y los industriales con capacidad exportadora relevante; esto excluye por supuesto, a toda la gama de capitales industriales pequeños y medianos. Como además el modelo privilegia el espacio circulatorio por encima del productivo, la situación es más crítica para estos últimos capitalistas a quienes el Estado deberá responder de modo compensatorio.

También el capital extranjero juega un papel muy importante. Para su caracterización en cada país se recomienda distinguir por los menos tres segmentos: a) las compañías que poseen inversiones directas en los países, a las cuales se les brindan mayores facilidades de operación y condiciones más ventajosas (tributarias por ejemplo); b) aquéllas compañías que son capaces de aprovechar y explotar el mercado nacional por la vía de las importaciones que realiza el país y, c) dado que el modelo usualmente se apoya en un fuerte endeudamiento externo, también representa un jugoso negocio para el capital financiero internacional (Valenzuela, 1991: 156-157).

El papel de los organismos multilaterales de crédito también es fundamental en este proceso de dominación de las economías nacionales. Para grandes sectores de la población latinoamericana es conocido que la política económica de cada país se discute también en la sede del Banco Mundial en Washington y que esto condiciona de modo determinante la política social que tiene que ver con las mayorías. El FMI sigue cumpliendo un importante rol no sólo económico sino ideológico como actor en este escenario.

Entre los claramente excluídos del modelo están no sólo los trabajadores y las trabajadoras no calificados/as y por tanto no articulados/as a los sectores del capital protagonista, sino amplios grupos de población. En la lógica de mercado imperante quedan fuera todas aquéllas personas que no sean “útiles” para la valorización del capital y la canalización máxima de excedentes. Estos sectores de población constituyen las mayorías latinoamericanas. A éstas también el Estado debe responder de algún modo.

El crecimiento exorbitante de la pobreza observado desde la década de los ochenta y acentuada en los noventa y persistente en el dos mil en América Latina, es la mayor evidencia de esta exclusión.

La respuesta estatal a esta problemática a través de la política social compemsatoria desarrollada desde los noventa y en la primera década del dos mil es absolutamente insuficiente comparada con las dimensiones acumuladas de la exclusión social. 


\section{La muerte del sujeto: algunas razones desde el llamado pensamiento posmoderno}

Desde los noventa se vienen planteando con mayor fuerza por parte de grupos académicos y de amplios sectores de la sociedad civil organizada los grandes dilemas éticos de nuestro tiempo. Como se deriva del apartado anterior, en la perspectiva económica, éstos se expresan de manera muy simple y muy compleja a la vez: ¿la organización económica está respondiendo a crear las mejores condiciones para la reproducción de la Vida (del ser humano y de la naturaleza) o sólo para la acumulación del capital? ¿la racionalidad económica formal niega o fortalece al sujeto?

Esto nos sitúa en el camino de seguir rastreando otras razones que constribuyen a sostener una lógica de muerte, ahora en la llamada posmodernidad.

En algunos textos contemporáneos como el de A. Klappenbach (1990) se sugiere la importancia de trabajar la ética vinculada al llamado pensamiento posmoderno para entender la situación actual. En tal sentido, se recuperan algunas reflexiones pensando en las posibles razones que contribuyen a la negación del sujeto.

El llamado pensamiento posmoderno se caracteriza por una serie de "muertes y finales": la muerte del sujeto, de la historia, de la razón, el fin de los relatos de emancipación, de las ideologías, muertes todas ellas anunciadas por la proclama nietzschiana de la "muerte de Dios”, resumen y paradigma de tantas defunciones...

Siguiendo la tradición de la filosofía de la sospecha, no se trata de muertes naturales sino de asesinatos. Y esto conduce inevitablemente a la ética: como decía Nietzsche, en la ética se revela la verdadera intención de toda filosofía, su trasfondo oculto y a veces inconsciente. La ética no constituye una aplicación de una teoría gnoseológica o metafísica sino "el germen verdadero de donde nace la planta completa”. Y haremos bien en preguntarnos “¿a qué moral deben (o quieren) conducirnos?... (Klappenbach, 1990:11)

Consideramos que es importante aceptar que todo pensamiento social se nutre de una determinada manera de concebir las relaciones sociales, o sea, de una ética, cuya explicitación y crítica resulta indispensable para comprender construcciones teóricas. Existe una red de relaciones que constituyen al sujeto pensante, entre las cuales las relaciones sociales ético-políticas resultan decisivas.

En este sentido, la pretendida "neutralidad" de la propuesta posmoderna es engañosa, sin embargo; tenemos que conocerla y desenmascararla pues está influyendo en la manera de pensar, sentir y relacionarse no sólo de amplios sectores de la población especialmente en las sociedades postindustriales sino también, en las sociedades de los países del sur, pues dadas las diferentes estrategias globalizadoras es cada vez 
más difícil delimitar fronteras de influencia de tal o cual hecho o corriente de pensamiento.

F. Lyotard caracteriza "la condición posmoderna como el fin de los metarrelatos de emancipación, ya no es posible inscribir los sucesos cotidianos en una gran historia con sentido propio, éste último ha estallado en fragmentos y no existe un único juego de lenguaje capaz de dar cuenta de los distintos niveles de realidad. Y ello no por una decisión de sus actores sino por la constatación pura y simple de que esos metarrelatos ya no están allí, ya no resultan disponibles...” (Lyotard, 1986)

- Existen diferentes posturas en el fenómeno posmoderno. Picó (citado por Klappenbach, 1990) ofrece una clasificación de por lo menos tres vertientes: neoconservadora, reconstructora-reformista y desconstructora posmoderna. Sin embargo, hay un denominador común en estas posturas como es el rechazo al establecimiento de un principio o fundamento único, último y normativo que cohesione los distintos órdenes de la cultura lo cual expresa una ruptura con las categorías modernas que, aunque se fueron transformando, no renunciaron a lo que era esencial: la postulación de un fundamento unitario que permitía entender un desarrollo histórico concebido como superación de etapas anteriores.

- Aparecen así algunos síntomas importantes de considerar, como son: la presencia creciente de una lógica hedonista y reduccionismos como los de Fukuyama para quien la historia ha terminado no porque hayan desaparecido los metarrelatos sino porque uno de ellos se ha cumplido. Por eso en su lógica, el capitalismo no tiene alternativas posibles. Luego entonces, hay que vivir el hoy lo mejor posible, lo más placenteramente posible en esta situación, en este estado de cosas que no podemos cambiar porque no hay alternativas posibles y menos aún, viables.

- Desapareciendo todo fundamento, el sentido estalla en fragmentos pues todo sentido implica un criterio en base al cual se establece el valor de aquello que se trate, lo nuevo del pensamiento posmoderno es el no responder al problema del sentido, lo cual no significa caer en el absurdo (como en el existencialismo de posguerra), sino implica el descubrimiento de que se puede vivir con sentidos parciales y hasta contrapuestos...ser posmoderno implica convivir de modo no traumático con la falta de sentido (Klappenbach, 1990: 26-27).

- Se presenta una aparente contradicción entre un sistema que aparece cada vez más inmodificable, absorbente y controlador y un modo de vida más individualista, hedonista y libre. El poder se está ejerciendo de otro modo en las sociedades postindustriales, vinculando coerción, placer y verdad. Como plantea Foucault, el poder está distribuyéndose según una compleja red de relaciones en todos los niveles sociales. En las sociedades del tercer mundo todavía mantiene su carácter coactivo y represivo.

- Esta «nueva cultura» requiere crear realidad para no sucumbir, esto 
se logra a través del simulacro, concepto desarrollado sobre todo por Baudrillard. El simulacro consiste en «una suplantación de lo real por los signos de lo real, es decir, de una operación de disuasión de todo proceso real por su doble operativo...». Es necesario crear un espacio hiperreal que llene de contenido a los símbolos culturales, ocultando así el gran secreto posmoderno: que detrás de ellos no hay nada (Baudrillard, citado en Ibid: 38).

- Entonces, la realidad se crea, se produce; las cosas y los hechos existen en la medida en que aparecen en televisión: los «medios de comunicación» son ante todo «medios de producción» de realidad. Hoy el valor se ha independizado de todo sustrato material, la «marca» ha desalojado el último resto de realidad del objeto y lo ha convertido en hiperreal (Klappenbach, 1990: 38-39).

Se abandona así el concepto tradicional de «sujeto». El sujeto no es algo que subyace, como lo expresa la etimología de la palabra (resumen de siglos de pensamiento sustancialista). Es más bien un cruce de coordenadas, el lugar de encuentro de ejes de significado ninguno de los cuales determina a los demás, como lo han creído los diversos humanismos que se han ido sustituyendo unos a otros...Cada uno de estos ejes constituye al sujeto, lo crea como tal, y no se limita a añadir determinaciones a un sustrato preexistente.

\section{¿Consumo que produce sujetos? \\ desde las abiertas o sutiles formas de manipulación de los deseos}

En las sociedades capitalistas, la noción de necesidad se ha transformado en la noción de demanda, y esto es fundamental en la lógica del sistema dominante puesto que la satisfacción de las necesidades es un medio para producir riqueza; de este modo, se induce la creación de «nuevas necesidades» en función de estimular una producción y un consumo que generen cada vez mayores ganancias. Pero además, se ha producido una gran confusión entre los conceptos de necesidades y deseos y esto no es accidental. En el marketing empresarial, se trata de producir placer y «bienestar» en los consumidores dando satisfacción a la demanda, a los deseos, y éstos son presentados como necesidades (Mo Sung, 1998). Todo parece reducirse a deseos y toda experiencia de placer parece reducirse a la satisfacción de los deseos, mientras más cueste satisfacerlos más se experimenta el goce placentero que esto produce.

Se corre permanentemente el peligro de reducir y confundir todas las necesidades humanas -biológicas y no biológicas- a deseos que luego en el mercado su satisfacción se expresa en acciones compulsivas de consumo. Los deseos no tienen límites, en la medida que se tenga o se posea algo, siempre faltará algo más.

Como sabemos, la dependencia económica y tecnológica ha ido acompañada de dependencia cultural y en ésta última el deseo mimético está cumpliendo un papel fundamental. Ya Fukuyama alentaba la produc- 
ción de riqueza como requisito para la satisfacción de la mayor cantidad de deseos-necesidades.

Así se pretende justificar el consumo suntuario de hoy en aras de que será una necesidad en el mañana y esto es muy peligroso puesto que la pobreza y la exclusión de hoy se explican por la riqueza apropiada por una minoría muy determinada y de costosísimos caprichos.

El problema se complejiza cuando se le ve desde la propuesta posmoderna, en la que los lazos sociales se fragmentan en infinidad de espacios más o menos privados y se produce una búsqueda generalizada de espacios también privados de realización personal como respuesta al carácter anónimo y omniabarcante del poder. El sujeto, que ha renunciado a cualquier interpretación sustancialista de sí mismo, se define por su participación en esa compleja red de actividades que pueden resumirse en el consumo, tomando la palabra en su sentido más amplio. Su participación en el consumo resulta así su manera de participar en el poder. El consumo es intercambio, un consumidor no está jamás solo y no se trata sólo de consumo de objetos pues el crecimiento del sector servicios en las sociedades postindustriales ha extendido el concepto de consumo hacia áreas nuevas como: la educación, el ocio, la cultura, el arte y hasta la política.

Eficacia y hedonismo pueden coexistir en un individuo sin que surja en él la necesidad de una autenticidad propia de épocas construidas sobre un fundamento unitario que hoy ha estallado en fragmentos. Este es uno de los resultados sociológicos de la «muerte del sujeto»: podríamos decir, simplificando en exceso, que si antes se podía hablar de un sujeto que consume, hoy estamos ante la presencia de un consumo altamente diversificado que produce sujetos (Klappenbach, 1990: 52).

\section{Ética y derechos humanos: por la defensa del sujeto viviente}

¿Si el sujeto ha muerto, tiene sentido hablar de derechos? Estas muertes tienen consecuencias muy importantes en el campo de la ética. Si quien es responsable de la acción moral, como plantea un amplio sector del pensamiento posmoderno, se ha convertido en un cruce de coordenadas históricas, parece claro que la misma noción crítica queda seriamente afectada. Al morir el sujeto muere también con él la posibilidad y todo criterio para cuestionar determinada situación histórica. Entonces ¿qué pasa con la ética y con sus principios fundamentales?

Klappenbach plantea que la "ética débil” que correponde al “pensamiento débil” impone tambien la renuncia a la otra característica que Kant consideraba constitutiva de la experiencia moral, como es la universalidad: en el diálogo o la conversación sólo cuentan quienes están sentados a la mesa y pueden por tanto expresar sus acuerdos y debatir sus discrepan- 
cias. La hermeneútica moral de una situación determinada parece dirigirse más al microgrupo que a la humanidad en su conjunto donde la mayoría de seres humanos no tiene cabida en el diálogo. Si a esto se suma la renuncia al sentido fuerte de la verdad que lleva consigo una renuncia al bien en su carácter absoluto y fundante de la acción moral, entonces, el dilema parece no tener salida.

Estamos entonces ante una situación crítica pues si por una parte el fin de la metafísica abre la posibilidad de despojar a la ética de un lastre ideológico encubridor, por otro la priva de un carácter categórico que parece esencial a la experiencia moral y que la distingue radicalmente de otros imperativos (Klappenbach, 1990: 87-88).

Desde una mirada ética a la economía se impone un discernimiento fundamental, o se sigue fortaleciendo una ética de mercado totalizante o se avanza en una opción ética por la vida del ser humano y de la naturaleza que, supone enfrentar una lógica de muerte.

Se escucha un clamor del sujeto por una Etica de la Solidaridad, por una Etica Económica Justa, por una Etica de la Liberación como plantea Enrique Dussel (1998) para enfrentar la exclusión y la extensión del dolor individual y social que debe traducirse en acciones decididas de todas y todos los que creen que es posible lograr aún en la tierra las condiciones para una vida digna y plena para los hombres y las mujeres de carne y hueso.

En el campo de los Derechos Humanos se expresan también más nítidamente los grandes dilemas y tensiones de nuestro tiempo, creemos que es donde se impone una reflexión profunda de las relaciones sociales concretas que es el "lugar" de la ética.

En la actualidad se observa que, en las relaciones internacionales la ética del "simulacro" muestra su verdadera naturaleza; ante el fundamento perdido se imponen una multitud de simulacros para que los/as espectadores/as se complazcan ante los escenarios maquillados y encubridores.

Pero ¿por qué hoy se habla y se permite tanto espacio para hablar de los derechos humanos? El problema es nuevamente situar quién(es) y desde dónde se habla de derechos humanos, ¿es desde los/as excluidos/as y las víctimas de la estrategia dominante de la globalización o, desde sus protagonistas? Diríamos que hoy están presentes ambas opciones en conflicto.

Es fundamental la comprensión de la lógica económica dominante, de la lógica de mercado que subyace a la estrategia de globalización neoliberal pues en ella se imponen criterios para la eficiencia, la competitividad, la captura de mercados y el despliegue del capital en un mundo "sin fronteras". Las consecuencias adversas de esta lógica en los seres humanos y en la naturaleza son asumidas y explicadas como necesarias temporalmente mientras los mecanismos se perfeccionan. No es el 
modelo o las políticas económicas las que esencialmente generan pobreza, desempleo y mayor marginación sino que son las "imperfecciones normales” del mercado. Así, cuando se plantea la defensa de los derechos humanos que surgen de la afirmación del ser humano como ser natural, como ser social, constituyen distorsiones del mercado a la luz del perfeccionamiento del engranaje de este Mercado en el proceso de globalización. La actual estrategia de globalización entiende los derechos humanos como derechos del poseedor, del propietario (Hinkelammert, 1998).

Los integrantes del Foro de Davos -de las más de 1000 multinacionales más importantes del planeta-, los organismos multilaterales y los gobiernos de la mayoría de países del mundo desarrollado hablan de estos derechos humanos. Justamente quienes concentran el poder económico, político y militar en el mundo.

Desde los/as pobres, desde los/as excluídos/as se pugna por el primer derecho a ser Sujeto -en su dimensión personal y colectiva-, se lucha por el reconocimiento y las garantías del ejercicio de los derechos como seres humanos en el espíritu de la Declaración de 1948 y más allá de ella. Éstos son un conjunto de derechos universales, no separables, no divisibles: los derechos económicos, sociales y culturales; los derechos civiles y políticos; los derechos sexuales y reproductivos, entre otros. Citamos esta gama de derechos porque no por casualidad están en el centro de confrontaciones actuales: el derecho como hombres y mujeres de participar como ciudadanos/as libres en las decisiones políticas y económicas, en las políticas ambientales, en la cultura y, por supuesto en las decisiones sobre el propio cuerpo.

Se tiene que dar una mirada crítica al ejercicio de estos derechos hoy junto al gran tema de la libertad, sobre todo ante la embestida del conservadurismo y de los fundamentalismos de diverso tipo, entre ellos el económico. La defensa de la universalidad e indivisibilidad de los derechos humanos es una tarea de primordial importancia, la cual pasa por la denuncia y confrontación de la lógica de mercado que pretende convencer del paraíso posible cuando en realidad éste lleva sistemáticamente a la exclusión no sólo de personas sino de países enteros.

\section{Fuentes de criterios para la defensa del sujeto}

Es fundamental considerar la corporeidad como fuente de criterios para una ética solidaria, los cuerpos vivientes como fuente de criterios tienen que prevalecer para enfrentar una lógica de mercado totalizante y todas sus mediaciones.

Entre los aportes más significativos de los diversos movimientos sociales de las últimas décadas y la producción de conocimiento que los ha acompañado, está la recuperación del concepto de la diferencia vinculado a temas sustanciales como la autonomía, la pluralidad, la tolerancia, la solidaridad. 
Se ha dado un interesante debate entre los conceptos de igualdad y diferencia no sólo en los movimientos feministas sino en todos aquellos espacios colectivos en los que se expresa la reivindicación de lo particular y lo propio: la raza, la edad, el sexo, la condición social, entre otros. Hay diferentes posturas en las que sería interesante profundizar pero, nos parece que hay un consenso mayor respecto a considerar que cuando se lucha por la igualdad de oportunidades para todas y todos no significa negar con esto la diferencia sino, por el contrario, tomarla en cuenta pues nadie tiene derecho de excluir a otra persona en razón de su sexo, raza, edad, religión o condición social. Tomar en serio la diferencia implica justamente la imposibilidad (ética) de dominación.

Una de las principales críticas a la filosofía occidental es que ésta ha sido muy a menudo una ontología: una reducción de lo Otro al Mismo. "En la experiencia ética, anterior a toda ontología, es donde aparece la verdadera alteridad, la única "diferencia” absolutamente irreductible a la mismidad del sujeto. "Lo absolutamente Otro es el Otro” (Levinas). La relación ética constituye una revelación del ser como exterioridad: no se fundamenta en el sujeto ni en un ámbito común a los términos de la relación, como sucedería con cualquier criterio de igualdad. El Otro aparece como rostro, es decir, no en cuanto a sus poderes o atributos sino "en cuanto otro", en la "dureza inamovible de su para sí”, desnudo de todo aquello que no sea su propia alteridad. "El rostro se niega a la posesión, a mis poderes. En su epifanía, en la expresión, lo sensible aún apresable se transforma en resistencia total a la aprehensión” (Klappenbach, 1990: 211).

Esta alteridad es también universal, ya que la misma experiencia ética en que se manifiesta rechaza todo límite empírico y revela "al otro en cuanto otro", absuelto de toda limitación espacio-temporal. La ética se convierte así en re-conocimiento de la realidad: la aceptación de que la relación social exige normas de acción diferentes a las que rigen la relación con las cosas.

Según Foucault, "el otro es indispensable en la práctica de uno mismo para que la forma que define esta práctica alcance efectivamente su objeto, es decir, el yo. Para que la práctica de uno mismo dé en el blanco constituido por ese uno mismo que se pretende alcanzar resulta indispensable el otro". El otro es pues esencial en la constitución de la propia subjetividad permaneciendo totalmente diferente de nosotros mismos. Es nosotros aun siendo otro como diría E. Morin. Este autor también propone que se debe hacer toda una reconstrucción conceptual en cadena para concebir la idea de sujeto.

...Porque si no partimos de la organización biológica, de la dimensión cognitiva, de la computación, del cómputo, del principio de exclusión, del principio de identidad, etc., no llegaremos a enraizar el concepto de sujeto de manera empírica, lógica como fenómeno. Es un principio que, de manera paradójica, es mucho más lógico que afectivo. Es una estructura organizadora. Y creo que esta no- 
ción de sujeto nos obliga a asociar nociones antagónicas: la exclusión y la inclusión, el yo, el ello y el se. Para esto es necesario lo que llamaré un pensamiento complejo, es decir, un pensamiento capaz de unir conceptos que se rechazan entre sí y que son desglosados y catalogados en compartimentos cerrados. Sabemos que el pensamiento compartimentado y disciplinario aún reina en nuestro mundo. Este obedece a un paradigma que rige nuestros pensamientos y nuestras concepciones según los principios de disyunción, de separación, de reducción. Sobre la base de estos principios es imposible pensar el sujeto asimismo pensar las ambivalencias, las incertidumbres y las insuficiencias que hay en este concepto, reconociendo al mismo tiempo su carácter central y periférico, significante e insignificante. (Morin 1994: 67)

El reto de pensar en el sujeto así es muy sugerente pero hay que aceptarlo sabiendo que al hacerlo se acepta también el conflicto personal y colectivo que esto supone para quienes venimos de una formación que está marcada por un pensamiento fragmentado y disciplinario, no holístico.

\section{A modo de conclusión: Por la afirmación del Sujeto}

La estrategia de acumulación de capital surgida en las últimas décadas y a la cual se le ha dado el nombre de globalización económica, se ha ido transformando en la peor de las amenazas globales que penden sobre la humanidad. Esta estrategia tiene como cimientos una concepción neoliberal de la economía, principios y supuestos hoy defendidos por los principales centros del capitalismo contemporáneo; tiene protagonistas, defensores decididos de una lógica de mercado totalizante, del individualismo y, justificadores de la exclusión de grandes grupos de población en el planeta y por ende, de la negación del sujeto.

Para estos grupos de poder no hay alternativas al capitalismo, se imponen simulacros cotidianamente a través de los medios de comunicación que se han convertido en "medios de producción de realidad”, de irrealidad que pretenden dotar de contenidos a sus nuevos símbolos culturales.

Se distorsionan necesidades, se explotan deseos, fomentando la participación en el consumo como la única manera de participar en el poder, al grado que antes hablábamos de sujetos que consumen pero, hoy en esta lógica, el consumo produce sujetos.

Para la defensa del sujeto y de la solidaridad es preciso comprender que, en esta estrategia los fines justifican todos los medios, aunque estos produzcan muerte; prevalece una racionalidad instrumental.

La racionalidad económica hay que asumirla pues frente a los medios y no sólo frente a los fines, se hace necesario asumir una racionalidad reproductiva, de vida, pues están en peligro las fuentes de la misma: el ser 
humano y la naturaleza. Hay que enfrentar lo que Hinkelammert denomina el suicidio colectivo.

Hay que recuperar y/o mantener una racionalidad del sujeto que irrumpe constantemente en la racionalidad formal afirmado si tu eres, yo soy. La racionalidad formal dominante niega esta racionalidad del sujeto y sostiene su contrario: si te derroto, yo soy.

Se tiene que volver al sujeto vivo, al sujeto que no puede vivir si no asegura que el/la Otro/a también pueda vivir, ubicándose esta posición más allá del cálculo de la razón instrumental. Esto lo hace desde la afirmación de la vida, recordemos que, la persona en tanto sujeto defiende sus intereses pero lo hace en la intersubjetividad establecida por el criterio según el cual la amenaza a la vida del otro/a es también amenaza para la propia vida, aunque “calculablemente”, en la relación costo-beneficio no se encuentren criterios para sostener eso.

En el contexto de globalización neoliberal, se están excluyendo desechando- como nunca antes en la historia, cuerpos vivientes. La economía como ciencia para la vida tiene que recuperar hoy corporeidades concretas en medio de abstracciones, de datos, de cifras, de modelos; tiene que entrar en diálogo con otras ciencias y saberes para recuperar su orientación y sus objetivos últimos. En tal sentido, creemos que miradas éticas de la economía y su quehacer basado en los derechos humanos, son fundamentales en la actualidad para contribuir desde su quehacer a afirmar al Sujeto, la Humanidad, la Vida. 


\section{Bibliografía}

Baudrillard, Jean (1978), Cultura y Simulacro, Ed. Kairos, Barcelona, España.

Cerutti Guldberg, Horacio (1997), Filosofías para la Liberación ¿Liberación del Filosofar?. Eds. CICSYH, UAEM, México.

Dussel, Enrique (1998), Etica de la Liberación en la edad de la globalización y de la exclusión. Editorial Trotta, Madrid, España.

Foucault, Michel (1981), Un diálogo sobre el poder, Eds. Alianza, Madrid, España.

Idem. (1979), Microfísica del Poder, Eds. De La Piqueta, Colección Genealogía del Poder, Madrid, España.

Gómez, Ricardo J. (1995), Neoliberalismo y Seudociencia. Lugar Editorial, Buenos Aires, Argentina.

Gonzáles Butrón, María Arcelia (2010), Etica de la economía. Reflexiones y propuestas de otra economía desde América Latina. Eds. UNAM y UMSNH, México.

Idem. (1999), Transformaciones económico estructurales, pobreza y desarrollo social en México. Eds. DEI, Costa Rica y CEMIF "Vasco de Quiroga”, México.

Hinkelammert, Franz (2003), Solidaridad o suicidio colectivo. Ambientito Ediciones, Heredia, Costa Rica

Idem. (1998), “El proceso de globalización y los derechos humanos: La vuelta del sujeto”. Revista Pasos No. 79, segunda época, DEI, Costa Rica, septiembre-octubre.

Idem. (1990), La deuda externa de América Latina. El automatismo de la deuda. Eds. DEI, San José, Costa Rica.

Idem. (1984), Crítica a la razón utópica. Eds. DEI, San José, Costa Rica.

Irigaray, Luce (1998), Ser Dos. Editorial Paidós, Argentina.

Klappenbach, Augusto (1990), Etica y Posmodernidad. Eds. Alcalá de Henares, España.

Lyotard, J.F. (1986), La condición posmoderna, Eds. Cátedra, Madrid, España.

Morin, Edgar (2003), Introducción del pensamiento complejo. Editorial 
GEDISA, Barcelona, España.

Idem. (1994). “La noción del sujeto”, En Nuevos paradigmas, cultura y subjetividad. Ed. Paidós, Argentina.

Mo Sung, Jung (1998), Desejo, Mercado e Religiao. Editora Vozes, segunda edición, Petrópolis, Brasil.

Nelson, Joan M. y colaboradores del Overseas Development Council (1991), Coaliciones frágiles: la política de ajuste económico. Eds. CEMLA y Banca Serfín. México, D.F.

Turner, Bryan S. (1989), El cuerpo y la sociedad. Exploraciones en teoría social. Eds. Fondo de Cultura Económica, México.

Valenzuela Feijóo, José C. (1991), Crítica del modelo neoliberal. El FMI y el cambio estructural. Eds. Facultad de Economía, UNAM, México.

Recibido: 15.10 .2012

Aceptado: 07.11.2012 